\title{
Development and Sizing of an Innovative System, Based on Natural Evaporation Processes and Convective Motions, for Salty and Brackish Water Depuration
}

Farné Stefano

Department of Industrial, Electrical, Computer and Biomedical Engineering, University of Pavia, Italy.

Copyright: (02020 Farné Stefano. This is an open access article distributed under the terms of the Creative Commons Attribution License, which permits unrestricted use, distribution, and reproduction in any medium, provided the original author and source are credited.

\section{ABSTRACT}

The need of replacing fossil fuels in many areas of human activities is strongly felt, in particular for the primary resource "freshwater", that must be regenerated, where the natural availability is not present or it has been depleted. The technologies for the production of desalinated water, normally make use of electrical (reverse osmosis) or thermal energy (distillation using gas / oils combustion) from fossil sources. The present paper is the continuation of the AJAST article, of the same author, Theoretical setting, mathematical model and operating principles of an innovative system, based on natural evaporation processes, for salty and brackish water purification, in which the innovative system named "Solar Desalination Geoassisted Continuous", covered by an Italian patent, registered by Vito Lavanga and Stefano Farné, was presented. In this paper, the SDGC plant is developed and sized for a case study, which can be used for a detailed design and the construction of a pilot plant.

Keywords: Desalter, Water, Purification, Depuration, Watermaker.

\section{Literature Review}

From the analysis of the scientific literature on the subject, and filtering the results on the basis of technologies comparable to the SDGC system, it is clear how the topic is being treated in depth from the technological point of view, while it is lacking in studies that give an economic analysis to allow a better understanding of the situation. This is mainly due to the highly experimental nature of much of the research, which is too recent to be able to extend the analysis to the economic and technical feasibility. In the MD field (membrane distillation) an interesting solution with graphene oxide membrane has recently been proposed (M. Nagapadma et al., 2019, p. 202). Moreover, the analysis shows that research on desalination systems, aimed at achieving production levels comparable with conventional technologies, finds fertile ground in HDH systems. Analysing the literature and comparing the various studies, it emerges that the common analysis data sees the main obstacle to the development of higher productivity in terms of distilled water. This aspect is dealt with in different ways: by improving the contact surface between the air and the water through the insertion of porous plastic elements to promote the humidification phase, as presented by (Chang, Zheng, Yang, Su, \& Duan, 2014, p. 254), who were able to increase productivity to $63.6 \mathrm{~kg} / \mathrm{h}$ with relatively contained specific costs of $4.4 \$ / \mathrm{m}^{3}$, or simply increasing the number of stages, as explored by (Hamed, Kabel, Omara, \& Sharshir, 2014; Reddy \& Sharon, 2014, p. 1081). In particular, the study on a double effect implant was developed by (Kang, Yang, Chang, Zheng, \& Duan, 2014) in which, even by the reuse of condensation heat and the heat possessed in the brine, it is possible to reach a range of $72.6 \mathrm{~kg} / \mathrm{h}$, at the expense of a considerable plant complexity compared to the solution proposed by (Chang et al., 2014, p. 254). A second solution is presented by (El-Agouz, Abd El-Aziz, \& Awad, 2014, p. 278) and consists of a variation of the method by which the feed water is introduced into the system; by spraying it through a spray system instead of using a rain dispenser, the evaporation and condensation phase is encouraged, obtaining $9 l$ distilled flow rate per unit area of solar collectors installed at relatively low cost, in the order of $0.03 \$ / l$. A third solution regarding the 
increase in the distilled product flow was analyzed by (Yildirim \& Solmus, 2014, p. 570) and (Bacha, 2013), according to which it is possible to increase the performance of the system by increasing the flow of air entering the system up to a limit (optimal value) beyond which it is no longer possible to obtain benefits. The same study also denied the thesis of ( $\mathrm{Li}$, Yuan, Wang, $\mathrm{Li}, \& \mathrm{Xu}, 2014$ ) according to which benefits could be obtained from preheating the incoming air for the purpose of increasing the relative humidity.

A second problem faced by the researchers mentioned concerns the uncertainty and the daily variability of productivity: the exclusive use of solar energy without accumulation systems to guarantee the needs (thermal and / or electric) causes a daily oscillation of the distillate flow rate, reducing its producibility. On the other hand, the integration of storage systems would increase total costs to the detriment of economic sustainability, but in the literature examined no comparative analyses were carried out to support this. The variability of the energy source is a problem that affects all renewable energy sources applied to any desalination technology; the study conducted by (Park, Schafer, \& Richards, 2012, p. 867-874) specifically analyses the effect of power variability on a reverse osmosis desalination plant fed directly by a wind energy plant, showing how, in the absence of power supply, a passage of salt occurs through the membranes, reducing the quality of the product. From this we can understand how the continuity of the energy source is important not only for the quantity of daily product, but also for its quality. At present, therefore, HDH systems are the ones most studied by researchers, who claim that systems of this type powered exclusively through renewable sources are applicable only on a small scale, due to the high investment cost, in relation to the production level reached.

In the literature there is also a limited contribution to the development of solar still systems: from the study carried out by (Manokar, Murugavel, \& Esakkimuthu, 2014, p. 310) it emerges that the system is influenced by a number of variables that cannot be controlled by man, including the available solar radiation, humidity and environmental temperature, meteorological conditions, and wind speed, while the parameters on which we can act are plant orientation, roof inclination, construction materials and process temperatures. The studies also show that the main problem concerns the large surface necessary to ensure satisfactory producibility in passive systems which increases the total costs of planting. To compensate for the need for space reduction with the achievement of a satisfactory range, some solutions have been developed: the use of auxiliary systems to preheat the feed water and thus increase the production per unit area has been addressed by (Reddy \& Sharon, 2014, p. 1081) through the use of solar collectors or with the aid of mirrors capable of increasing the incident radiation per unit area. The same study shows that the low performance of the plant is also due to the lack of recovery of latent condensation heat, which can only be used in multi-effect plants with significantly increased plant costs. A second study addressed by (Ayoub \& Malaeb, 2014, p. 29) instead provides for increasing the evaporating surface by inserting a rotating cylinder into the system. The study argues that, according to the calculations performed, with this system productivity can be improved by an order of $200-300 \%$ compared to standard passive systems. This allows the reduction of the surface required for equal productivity; however, this solution is reflected in the specific production cost, which varies in the order of $6-30 \$ / \mathrm{m}^{3}$ and is higher than conventional passive systems due to the increased complexity of the system and therefore higher operating costs. 
Still in the field of technological solutions powered by renewable sources, (Reddy \& Sharon, 2014, p. 1083) analyze the operation of solar chimneys, showing how, as a passive system, the operation cannot be prolonged efficiently beyond $8 h / d$, by virtue of the amount of useful solar radiation available. This is negatively reflected in the producibility and the specific production costs, evaluated by experimental plants as $2.23 \$ / \mathrm{m}^{3}$. The study also shows that the structure of these plants is large and very complex, which therefore implies high implantation and operating costs (not reported in the literature). To compensate for these costs, the system can be integrated with a series of wind turbines for the production of electricity.

Even traditional technologies, specifically the MSF plants, are being studied. These plants, typically adopted for high production, are generally fed from fossil sources. The aim of these studies is to replace conventional sources with economically sustainable technologies in the long run. The study conducted by (Reddy \& Sharon, 2014, p. 1085) states that the use of MSF plants powered by solar energy can reach production orders up to 30 times higher than that achieved with solar still systems and with lower costs. Often, however, the energy produced by solar plants is not sufficient to cover the needs (given the randomness of the source itself) and they are therefore often coupled to power plants, in order to use the waste heat. An interesting study conducted by (Salata \& Coppi, 2014, p. 614) plans to use solar ponds together with an absorption heat pump to preheat sea water to a temperature around $100{ }^{\circ} \mathrm{C}$. According to the study, in fact, thanks to the high concentration gradients of the salts between the surface and the bottom of the solar ponds, there is a temperature inversion effect that brings the lowest layer of water to a higher temperature than that on the more superficial surface. Under the right conditions, solar ponds with depths of over one meter have a temperature difference of $50-60{ }^{\circ} \mathrm{C}$, which maintains average values throughout the year (Ramadan, El-Sebali, Aboul-Enein, \& Khallaf, 2004, p. 64), making it usable as a seasonal solar thermal energy collector. However, the study shows that, given the high surface area required for solar ponds, the system is only suitable for small-scale installations.

Another solution presented by (Kabeel \& El-Said, 2013, p. 12) introduces a change to the MSF solar-powered system. By exploiting flash evaporation like traditional systems, it uses a heat carrier fluid enriched with nano-particles that favors the performance of the plant in terms of productivity. This makes the MSF system practicable on a small scale and it can reach specific levels up to $7.7 \mathrm{l} / \mathrm{d}$ per unit area of solar collectors. To date, estimated production costs are quite high, in the order of $11.7 \$ / \mathrm{m}^{3}$, and the installation costs (not shown) are mainly due to the cost of the collectors and of the water heating system. It is expected that increasing the performance of this portion of the system will reduce the specific cost by $63 \%$.

The literature also reports some experimental plants built with the aim of obtaining an autonomous system that can be used to purify water in areas without adequate infrastructure for water supply. The study conducted by (Schafer, Remy, \& Richards, 2004, p. 233-243) analyses the functioning of a desalination plant that combines solar technology with a membrane system, fed by waters with different chemical composition. The results show how, while using a simple and inexpensive system, the plant is able to produce drinking water with specific consumption varying between $5.5 \mathrm{kWh} / \mathrm{m}^{3}$ and $26 \mathrm{kWh} / \mathrm{m}^{3}$ according to the degree of salinity of the incoming water. The use of membranes, however, raises a series of problems due to the phenomenon of fouling that characterizes this 
Asian Journal of Applied Science and Technology

Volume 4, Issue 4, Pages 105-129, October-December 2020

technology and which increase the maintenance costs of the plant. Since the membrane technology is widely adopted, there are several studies that analyse this complication with the aim of limiting its effects: the analysis conducted by (Nam, Seockheon, Dooil, Seungkwan, \& Ji, 2011, p. 1573-1579) studies the influence that the different materials constituting the membranes have on the phenomenon of dirtying them, while (Cervinia, Masaki, Tetsuji, Satoshi, \& Wataru, 2016, p. 308-318) studies the effect of biofilm formation on the inorganic suspended solids accumulated inside the membranes, highlighting how a very thorough pre-treatment of the feed water is fundamental in membrane systems, to avoid further aggravating the membrane fouling.

The literature review presented in this section shows how the research on evaporative desalination systems powered by solar energy is full of potentially valid solutions, but that these still have some limits that have not been completely overcome. As can be deduced from the previous lines, researchers are grappling with the need to obtain satisfactory production levels while keeping the complexity of the system, and therefore the related costs, at economically sustainable levels.

From the solutions presented, we note how the superficial encumbrance of the systems is a limiting factor for the applicability of some large-scale systems, both for technical issues related to the possibility of realization, and for economic issues related to installation costs in relation to the production level obtainable.

Another critical issue concerns the operation of the plants: the exclusive exploitation of solar energy, without the addition of energy storage systems, makes the production of fresh water erratic and subject to weather conditions. The randomness of solar energy, characteristic of all renewable sources, limits the operation of the plant to only daylight hours, thus increasing the cost per unit of production and compromising the quality.

The analysis of the state of the art therefore shows that the new systems fed through the exclusive exploitation of solar energy cannot yet be used for the desalination of large quantities of water. On the contrary, the integration of solar energy systems with traditional plants is the most satisfactory solution: as presented in paragraph 2.3.1, even if they do not reach the production levels of the technologies powered by conventional sources, they can produce up to a hundred daily cubic meters at a cost that would allow them to be used.

\section{SDGC Plant}

The SDGC process (Solar Desalination Geoassisted Continuous) is an innovative thermal distillation process that is essentially based on a first air humidification phase and a second phase of air dehumidification, exploiting, at steady state, only solar thermal energy. The method and the operating principles to obtain the purified water has been described in the paper Theoretical setting, mathematical model and operating principles of an innovative system, based on natural evaporation processes, for salty and brackish water purification (Farné S., AJAST (2020), Volume 4, Issue 3, Pages 183-209). In what follows, a detailed description of the SDGC invention is presented.

The invention is described with reference to the figures 1 and 2 , in which:

- figure 1 is a perspective view of the device according to the invention;

- figure 2 is a view in section, obtained by a transverse plane, of the device according to the invention. 


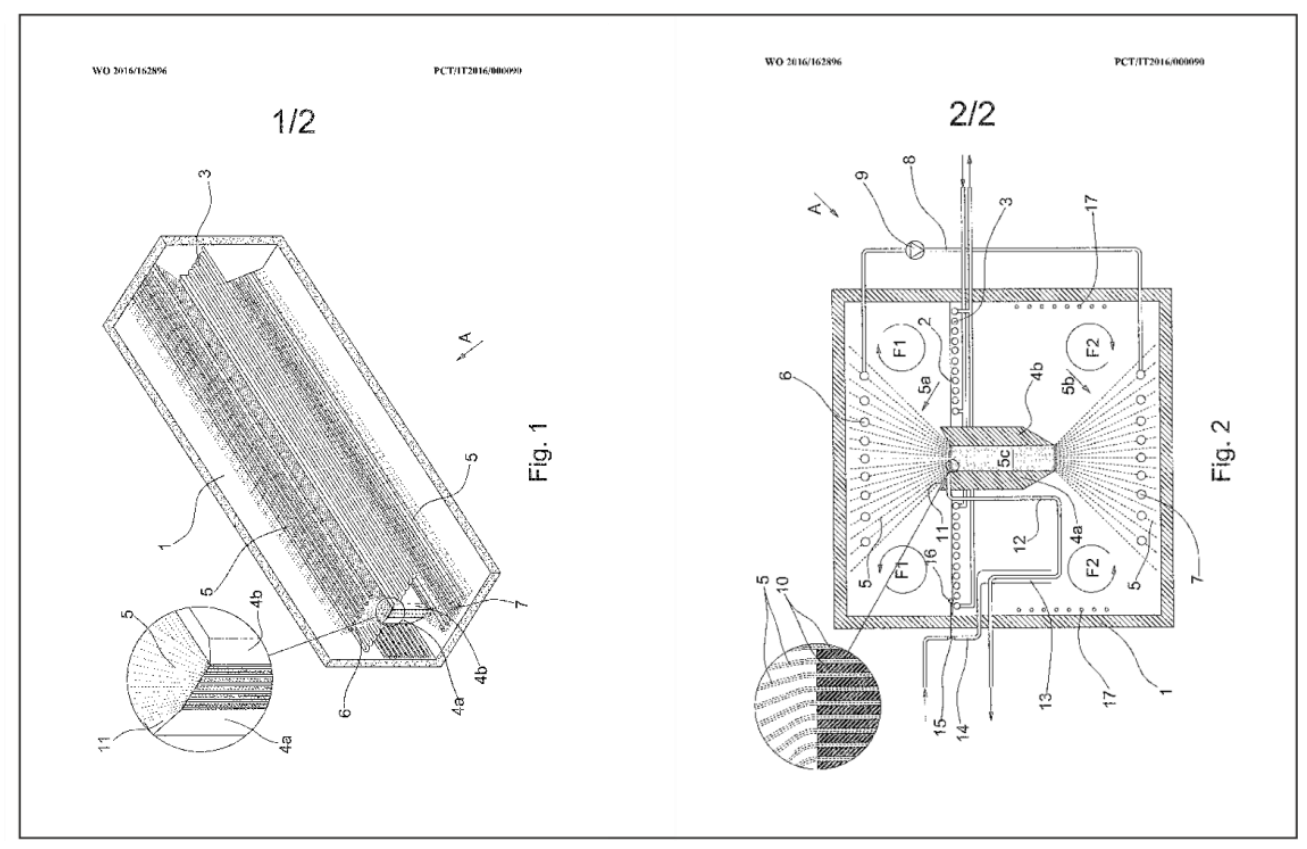

With reference to the figures 1 and 2, with (A) it is shown a device, according to the invention, to desalinate sea water, brackish water or from industrial processes. Said device (A) includes a tank (1), preferably waterproof and thermally insulated, having the shape of a parallelepiped, filled in with the water to desalinate for about two thirds of the volume. In alternative, the tank (1) have a cylindrical or similar shape, with horizontal generators. Just below the free surface of the water (2), it is located a first heat exchanger (3), for example consisting of a bundle of pipes run through by a heating heat transfer fluid, preferably, by a thermal or geothermal or solar system (not represented), said first heat exchanger (3) having the function to heat the water to produce steam. The heat transfer fluid enters the first exchanger (3) from the central side, as shown in fig. 2, and exits from the peripheral side, in order to carry more heat into the central parts with respect to the peripheral ones. This fact allows to trigger the convective motions, as indicated by circular arrows (F1) and (F2), respectively, in the gaseous and liquid phases, the purpose of which will be clarified below. At about the halfway point of the height of the tank (1), they are positioned two bars $(4 \mathrm{a}, 4 \mathrm{~b})$ which extend over the entire length of the tank (1) itself, whose function will be explained below. The bars $(4 \mathrm{a}, 4 \mathrm{~b})$ are positioned on a multiplicity of metal sheets (5) opened like a folding fan, both above (5a), and below (5b) of the bars (4a, 4b). In the part between the bars ( $4 a, 4 b)$ the sheets (5) are compact, while in the part opened like a folding fan, both above (5a) and under (5b), they are stretched with the dual purpose of exposing more specific surfaces and to allow the passage of fluids through them. Said metal sheets opened like a folding fan (5a) upwards have the function of cooling means because they cause the steam cooling, obtaining the condensation. Besides said metal sheets opened like a folding fan (5b) towards the bottom have the function of heating means because they cause the heating of the underlying mass of water, in which they are immersed. As an alternative to the stretched metal (5), it can be used the metal thatch (not shown) which, in respect of a shorter duration, offers the advantage of having a greater specific surface area favoring, therefore, the condensation of the steam. In the upper fan (5a) of the stretched sheets (5) a second heat exchanger (6) is placed, while in the lower fan (5b) a third heat exchanger (7) is placed. Both said second and third heat exchanger $(6,7)$ are, for example, 
Asian Journal of Applied Science and Technology

Volume 4, Issue 4, Pages 105-129, October-December 2020

constituted by tube bundles placed in contact with the stretched sheets (5). The second and third heat exchanger (6, 7) are connected by a first pipe (8), run through a heat transfer fluid, pushed by a pump (9). The two bars (4a, 4b) are thermally insulated and the sheets (5), in the section between said two bars (4a, $4 b$ ) are treated so as to not allow water infiltration, for example by the interposition of a sealant (10), as shown in the enlarged details of figures, said sealant (10) being preferably thermally conductive, to enhance the passage of heat from the upper fan (5a) to the bottom (5b) one. In fact the group comprising the sheets (5) and the bars (4a, 4b) constitutes a sort of "thermal tunnel" (5c), as it is able to transmit heat between the upper fan (5a) and the lower (5b) one, without dispersing laterally, in that the bars themselves are thermally insulating. The upper edges of the bars (4a, 4b) are inclined towards the central side so as to constitute a storage put in communication with the outside through a second pipe (12). Said second outlet pipe (12) is in heat exchange connection, through a fourth exchanger (13), preferably in counterflow, fed by a third loading pipe (14) that feeds the tank (1) with water to desalinate and maintains a constant level (2) in the tank (1) itself, by means of a valve (15) controlled by a level relief device (16). It is provided a fifth heat exchanger (17), disposed along the side walls, whose function is to subtract heat to the water. This fact allows triggering convective motions, as indicated by the circular arrows (F2), the purpose of which will be clarified below.

The operation of the device according to the invention is as follows. The water to desalinate is heated by the first heat exchanger (3). The fact of being placed in nearness of the free surface (2) fosters the water evaporation, therefore the upper part of the tank (1) is brought to the condition of the water vapor saturation. When fully operational, in the tank is present the following situation (l):

- the water temperature in the nearness of the free surface (2) may be approximately between 40 and $70{ }^{\circ} \mathrm{C}$, preferably highest in the central zone, conditioning the upper fan (5a) towards similar temperatures;

- the water temperature into the depths may be approximately between 15 and $25^{\circ} \mathrm{C}$, conditioning the lower fan (5b) towards similar temperatures;

- the upper fan (5a) and the lower fan (5b), are so subjected to a thermal gradient through the thermal tunnel (5c), highly conductive, which allows a flow of heat which tries to reset the gradient;

- the saturated steam, above the free surface, coming into contact with the upper fan (5a), at a lower temperature, condenses in water and releases the latent heat, which contributes to maintain high temperatures on the upper fan $(5 a)$, continuing to feed a flow of heat towards the lower fan (5b) through the thermal tunnel $(5 c)$;

- the condensed and desalinated water is collected in the reservoir (11) and it is extracted through the second outlet pipe (12);

- by the third load pipe (14), the level of the free surface (2) is continuously maintained.

In order to increase the heat flow from the upper fan (5a) to the lower fan (5b), the third and fourth heat exchanger (6) and (7) are provided, connected by the first pipe (8), which is run through by a heat transfer fluid, pushed by the pump (9). The convective motions that occur into the steam, indicated by the circular arrows (F1), foster the flow of the steam itself towards the upper fan (5a), improving the heat exchange between the steam and the stretched metal 
Asian Journal of Applied Science and Technology

Volume 4, Issue 4, Pages 105-129, October-December 2020

sheet (5) and, therefore, the condensation. The convective motions that take place into the water, indicated by the circular arrows (F2), supports the water flow itself on the lower fan (5b), improving the heat exchange between water and the stretch metal sheets (5) and, therefore, the heat contribution towards the free surface (2). In this way it is established an aqueous counter-current flow stream with the upper gaseous flow, with the consequent increase of the evaporation rate. The convective motions in the water can be increased by cooling the same water in proximity of the walls of the tank (1), by means of the fifth heat exchanger (17). For the purpose of the heat recovery from the condensed water effluent, which runs through the second pipe (12), it is provided the fourth heat exchanger (13) which transfers the heat from the condensed water to the water to desalinate by entering, through the third pipe (14).

The described process is strongly fostered if the tank (1) is well thermally insulated, tending to adiabatic conditions, since it tends to a careful reuse of exploitable energies, organizing and supporting convective motions that make efficient desalting process, thanks to inertial dynamics, the action will also continue in the temporary absence of external support (for example in night-time hours).

\section{Main Materials and Components}

In this section it has been applied the mathematical model developed in the paper Theoretical setting, mathematical model and operating principles of an innovative system, based on natural evaporation processes, for salty and brackish water purification (Farné S., AJAST (2020), Volume 4, Issue 3, Pages 183-209). They have been established the operating conditions that will allow obtaining producibility in terms of condensate that can be compared with the technologies shown in Farné S., AJAST (2020), Volume 4, Issue 3, Pages 183-209. A main purpose is to tend towards the design of a standard model that can be representative of a subsequent economic analysis, trying wherever possible to use standardized elements and materials commonly used in the industry. The following paragraphs show an extract of the most important materials chosen for the analysis of the case study.

\subsection{Tank}

The tank in which the system is to be built must be large enough to allow the use of a surface that will allow the evaporation of an adequate quantity of water without causing the system to operate under particularly severe operating conditions. Furthermore, it must be deep enough to ensure that right temperature gradient is maintained.

Table 1. External dimensions of Gazebo C-15

\begin{tabular}{lll}
\hline Capacity & $\mathrm{m}^{3}$ & 50 \\
Width* & $\mathrm{cm}$ & 250 \\
Length* & $\mathrm{cm}$ & 950 \\
Height* & $\mathrm{cm}$ & 250 \\
\hline *External dimensions & & \\
\hline
\end{tabular}

The material constituting the tank must be resistant to corrosion caused by salt water, able to maintain the pre-set vacuum level inside, and be easy to install. Prefabricated reinforced concrete tanks were chosen, as commonly used 
Asian Journal of Applied Science and Technology Volume 4, Issue 4, Pages 105-129, October-December 2020 in water treatment plants. For the case study, the model C-15 of the company Gazebo S.p.A. was chosen, for which the data of interest are reported in Table 1 (Gazebo S.p.A., 2013). The company in question provides customers with the .dwg format files with all the measurements of the tank. Table 2 shows the internal measurements:

Table 2. Internal dimensions of Gazebo C-15

\begin{tabular}{lll}
\hline Width & $\mathrm{cm}$ & 230 \\
Length & $\mathrm{cm}$ & 930 \\
Height & $\mathrm{cm}$ & 230 \\
\hline
\end{tabular}

Figure 3 shows an example of a multiple installation of the type of tank considered.

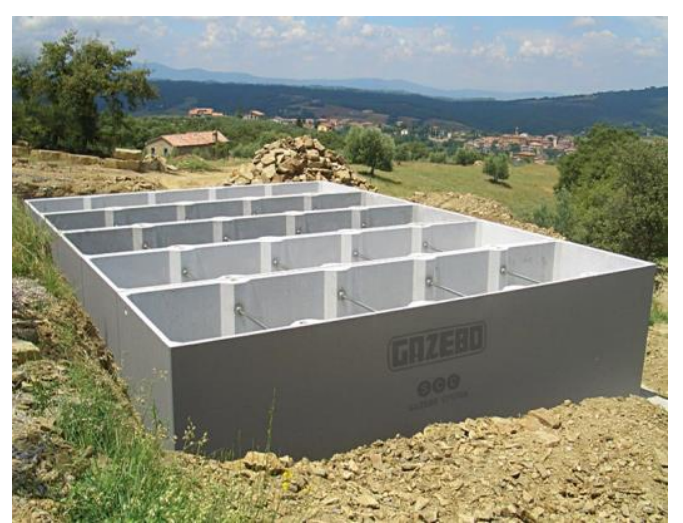

Figure 3. Example of tank considered

\subsection{Thermal insulation}

The tank must be thermally insulated in order to minimize dispersion to the external environment. to thermally insulate it, it was decided to use polyurethane foam panels and the GT model of the company Stiferite S.r.l. (Figure 4) was chosen. The technical data are shown in Table 3 (Stiferite S.r.l., 2017):

Table 3. Stiferite GT100 technical data

\begin{tabular}{lll}
\hline Thickness & $\mathrm{mm}$ & 100 \\
Thermal transmittance & $\mathrm{W} / \mathrm{m}^{2} \mathrm{~K}$ & 0.23 \\
Operating range & ${ }^{\circ} \mathrm{C}$ & {$[-40-110]$} \\
\hline
\end{tabular}

The panel is built with the sandwich technique, consisting of an insulating component in polyiso foam, expanded without using CFC or HCFC, coated on both sides with a Duotwin® Green system.

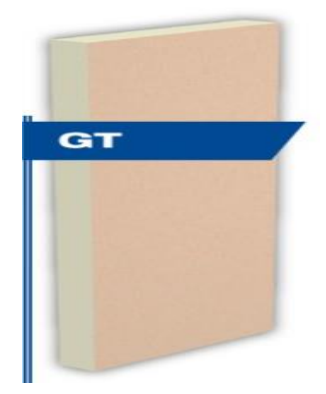

Figure 4. Foam panel (source: Stiferite S.r.1.) 
Asian Journal of Applied Science and Technology

Volume 4, Issue 4, Pages 105-129, October-December 2020

It has been chosen to install two superimposed panels of a total thickness of $200 \mathrm{~mm}$; this decision was motivated by economic considerations; in fact, in common building practice, $100 \mathrm{~mm}$ panels are widely used and, therefore, their use on a large scale makes them economically cheaper than a single double-thickness panel, as the latter is less widely used.

\subsection{Internal piping}

Inside the tank there is a main exchanger, which is needed to heat up and maintain the salt water at the proper temperature (contributing to the reintegration of the energy lost through the casing), and two safety exchangers, which are needed to restore the necessary thermal gradients that are the cornerstone of the whole system. For both uses, it was decided to use corrugated copper pipes, in order to guarantee an adequate degree of turbulence in the heat-carrying fluid and therefore promote heat exchange. These pipes are produced by the company Pantani Divisione Tubi S.r.l. (Figure 5) which is specialized in the construction of corrugated and finned pipes for heat exchangers. In addition to the above reasons, it is thought that due to the turbulence inside the corrugated piping micro-vibrations are created, which, when transmitted to the water promote its evaporation.

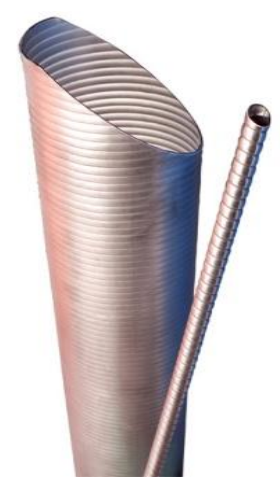

Figure 5. Corrugated pipes (source: Pantani Divisione Tubi S.r.l.)

\subsection{Expanded sheets - Thermal tunnel}

The material of which the thermal tunnel is made is of particular importance since it directly influences the plant's potential in terms of distillate production. The expanded metal is produced by a simultaneous process of cutting and lengthening sheets or rolls of solid sheet.

Table 4. Expanded metal technical data

\begin{tabular}{lll}
\hline Material & $/ /$ & Aluminum \\
Thickness & $\mathrm{mm}$ & 2 \\
Type of carving & $/ /$ & Rhomboidal \\
Carving measures & $\mathrm{mm}$ & $62 \times 20$ \\
Empty on full & $\%$ & $30 \%$ \\
Sheet measurements & $\mathrm{mm}$ & $1000 \times 2000$ \\
\hline
\end{tabular}

This process creates rhomboidal openings in the raw material that allow the passage of air, fluids and light. Stretched metal is chosen due to the fact that this product is commonly used in industry, so it costs less than other 
solutions that require tailor-made craftsmanship; moreover, it is a product that lends itself easily to the main mechanical processes such as bending, cutting, welding. For the case study, a expanded metal with rhomboidal mesh was chosen, produced by the company Fratelli Mariani S.p.A. and having the shape shown in Figure 6 and the characteristics shown in Table 4.

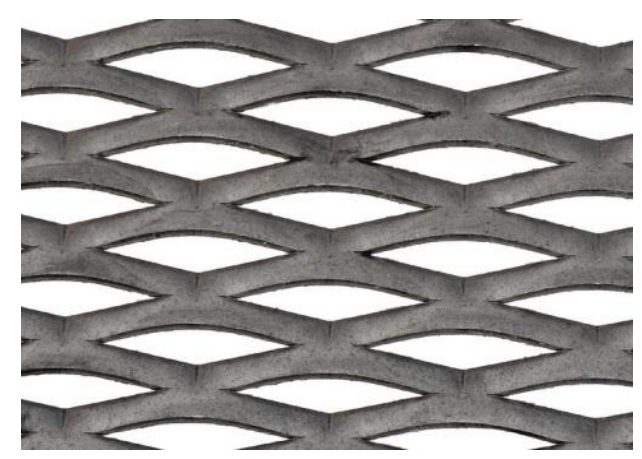

Figure 6. Expanded metal (source: Fratelli Mariani S.p.A)

Near the free surface, the pressed sheet metal side by side must constitute a region with a high thermal conductivity that can dispose of the heat in an efficient way, so as to allow a sufficiently rapid condensation process. To guarantee this function, near the free surface the sheets will be separated from the salt water through polyurethane foam panels (coated with aluminum to protect against salt corrosion) forming a compact sheet packet.

The ideal condition of heat transmission could be pursued if, when passing through the thermal tunnel, the sheet is interrupted, to resume near the salt water on the bottom of the tank. However, in this first phase, as mentioned at the beginning of the section, it has been tried to obtain a satisfactory result using standardized materials. Therefore, to fill the interstices that will inevitably be formed in the package of sheet metal side by side, liquid aluminum will be injected inside the structure.

\subsection{Air stirring system}

To achieve adequate process speeds, it is necessary that the convective motions developed inside the tank are characterized by a rather high speed, so as to push the evaporation and condensation phases to the maximum. To obtain this result it is possible to use tangential stirring systems powered by electric motors. In the future it will be possible to evaluate the feasibility of using the patented $\mathrm{MHML}^{\mathrm{TM}}$ mixing system; it consists of the appropriate assembly of materials commonly used in industry, such as draining and circulating tubes. The advantage of this solution consists in the simplicity of installation and in the drastic reduction of the energy dispersions typical of vortical processes (Lavanga \& Farnè, MHLM, 2017).

\section{Sizing}

The following section presents the result obtained following the application of the mathematical model developed in the paper Theoretical setting, mathematical model and operating principles of an innovative system, based on natural evaporation processes, for salty and brackish water purification (Farné S., AJAST (2020), Volume 4, Issue 3, Pages 183-209). All design choices have been carefully evaluated with the aim of achieving a good compromise between performance, production and costs. 


\subsection{Operating conditions}

The preliminary calculations led to consider a good level of obtainable productivity through the implementation of the following conditions:

- Work in vacuo;

- Artificial movement of indoor air;

- Adequate operating temperatures;

- Adequate evaporating surface: this condition is directly reflected in the size of the plant to be dedicated to the thermal tunnel;

- Transversal and longitudinal gradients: for optimal working, the distribution of salty water temperatures must be characterized by the formation of gradients between the free surface and the bottom of the tank (obtained through the stratification of the water) and between the center of this and the side walls (obtained through the appropriate arrangement of the delivery and return of the system).

Table 5 shows the operating conditions taken into consideration for the application of the calculation model.

Table 5. Operating conditions of the SDGC system

\begin{tabular}{lcl}
\hline Total pressure inside the tank & $\mathrm{Pa}$ & $30,000.00$ \\
Average salt water temperature in steady state (free surface) & ${ }^{\circ} \mathrm{C}$ & 60.00 \\
Humidified air temperature & ${ }^{\circ} \mathrm{C}$ & 60.00 \\
Dehumidified air temperature & ${ }^{\circ} \mathrm{C}$ & 30.00 \\
Total evaporating surface & $\mathrm{m}^{2}$ & 16.74 \\
Humid air speed & $\mathrm{m} / \mathrm{s}$ & 9.00 \\
\hline
\end{tabular}

Salt water is heated only near the free surface and only to the extent that it guarantees evaporation without achieving thermal equilibrium, a condition whereby the system would stop. The thermal stratification will allow the right temperature gradient to be achieved.

\subsection{Losses through the insulated tank}

As explained in the previous article, the losses through the casing are evaluated according to the conditions inside and outside the tank. For this case study, it was assumed that the tank was installed on a ground support, in the Milan area, where the average annual temperature is about $13^{\circ} \mathrm{C}$. Table 6 shows the result of the calculations performed, in which the limiting coefficient of water was obtained from (Calza, 2010, p. 126).

Table 6. Power loss from the tank

\begin{tabular}{llll}
\hline Wall stratigraphy & & & \\
\hline \multirow{2}{*}{ Layer } & Thickness & Conductivity & Transmittance \\
\cline { 2 - 4 } & $m$ & $W / m K$ & $W / m^{2} K$ \\
\hline External conductive coefficient & $/ /$ & $/ /$ & 25.00 \\
\hline
\end{tabular}




\begin{tabular}{|c|c|c|c|}
\hline Stiferite GT & 0.1 & 0.023 & 0.23 \\
\hline Stiferite GT & 0.1 & 0.023 & 0.23 \\
\hline CLS concrete & 0.1 & 1.600 & 16.00 \\
\hline \multicolumn{4}{|l|}{ Vertical wall (air/air) } \\
\hline \multicolumn{2}{|l|}{ Internal conductive coefficient } & $\mathrm{W} / \mathrm{m}^{2} \mathrm{~K}$ & 8.00 \\
\hline \multicolumn{2}{|l|}{ Total thermal transmittance } & $\mathrm{W} / \mathrm{m}^{2} \mathrm{~K}$ & 0.11 \\
\hline \multicolumn{2}{|l|}{ Total surface } & $\mathrm{m}^{2}$ & 19.02 \\
\hline \multicolumn{4}{|l|}{ Horizontal wall - Ascending flux (air/air) } \\
\hline \multicolumn{2}{|l|}{ Internal conductive coefficient } & $\mathrm{W} / \mathrm{m}^{2} \mathrm{~K}$ & 9.30 \\
\hline \multicolumn{2}{|l|}{ Total thermal transmittance } & $\mathrm{W} / \mathrm{m}^{2} \mathrm{~K}$ & 0.11 \\
\hline \multicolumn{2}{|l|}{ Total surface } & $\mathrm{m}^{2}$ & 21.39 \\
\hline \multicolumn{4}{|l|}{ Vertical wall (air/water) } \\
\hline \multicolumn{2}{|l|}{ Internal conductive coefficient } & $\mathrm{W} / \mathrm{m}^{2} \mathrm{~K}$ & 800.00 \\
\hline \multicolumn{2}{|l|}{ Total thermal transmittance } & $\mathrm{W} / \mathrm{m}^{2} \mathrm{~K}$ & 0.11 \\
\hline \multicolumn{2}{|l|}{ Total surface } & $\mathrm{m}^{2}$ & 34.80 \\
\hline \multicolumn{4}{|l|}{ Ground dispersion } \\
\hline \multicolumn{2}{|l|}{ Ground type } & type & sand/gravel \\
\hline \multicolumn{2}{|l|}{ Ground conductivity } & $\mathrm{W} / \mathrm{mK}$ & 2.00 \\
\hline \multicolumn{2}{|l|}{ Heat capacity per unit of volume } & $\mathrm{kJ} / \mathrm{m}^{3} \mathrm{~K}$ & 2000.00 \\
\hline \multicolumn{2}{|l|}{ Specific size (area / perimeter) } & $\mathrm{m}$ & 1.84 \\
\hline \multicolumn{2}{|l|}{ Total thickness of external perimeter walls } & $\mathrm{m}$ & 0.30 \\
\hline \multicolumn{2}{|l|}{ Internal surface thermal resistance } & $\mathrm{m}^{2} \mathrm{~K} / \mathrm{W}$ & 0.0013 \\
\hline \multicolumn{2}{|l|}{ Equivalent thickness } & $\mathrm{m}$ & 0.38 \\
\hline \multicolumn{2}{|l|}{ Thermal transmittance } & $\mathrm{W} / \mathrm{m}^{2} \mathrm{~K}$ & 1.80 \\
\hline \multicolumn{2}{|l|}{ Total surface } & $\mathrm{m}^{2}$ & 21.39 \\
\hline \multicolumn{4}{|l|}{ Power losses from the tank } \\
\hline \multicolumn{2}{|c|}{ Average annual outdoor temperature (Milan, Italy) } & ${ }^{\circ} \mathrm{C}$ & 13.00 \\
\hline \multicolumn{2}{|l|}{ Average internal temperature } & ${ }^{\circ} \mathrm{C}$ & 35.00 \\
\hline \multicolumn{2}{|l|}{ Power loss } & $\mathbf{k W}$ & $\mathbf{1 . 0 3}$ \\
\hline
\end{tabular}

\subsection{Evaporated flow rate}

The determination of the quantity of evaporating water represents a fundamental point of the process, primarily because knowing this allows to establish the maximum value of condensate that it is obtainable in the real conditions and secondly because in this way it is also possible to evaluate the flow rate of salty water to be 
reintegrated into the system. The total evaporating surface is divided in half by the presence of the thermal tunnel, both halves operating under the same operating conditions; this allowed performing the calculation on one of the two halves of the tank and then extending it to the entire evaporating surface. Table 7 shows the results obtained from the application of the model.

Table 7. Total water flow

\begin{tabular}{|c|c|c|c|}
\hline \multicolumn{4}{|l|}{ Physical state of water on the free surface } \\
\hline Hygrometric degree & & // & 1.00 \\
\hline Saturation pressure & & $\mathrm{Pa}$ & $19,943.76$ \\
\hline Partial vapor pressure & & $\mathrm{Pa}$ & $19,943.76$ \\
\hline \multicolumn{4}{|l|}{ Physical state of dehumidified water } \\
\hline Kinematic viscosity & & $\mathrm{m}^{2} / \mathrm{s}$ & 0.0000162 \\
\hline Hygrometric degree & & $/ /$ & 1.00 \\
\hline Saturation pressure & & $\mathrm{Pa}$ & 4246.03 \\
\hline Partial vapor pressure & & $\mathrm{Pa}$ & 4246.03 \\
\hline \multicolumn{4}{|l|}{ Other data } \\
\hline Specific size & & $\mathrm{m}$ & 0.90 \\
\hline Universal constant of perfect gases & & $\mathrm{J} / \mathrm{kmolK}$ & 8314.00 \\
\hline Molar mass of water & & $\mathrm{kg} / \mathrm{kmol}$ & 18.00 \\
\hline Binary diffusion at the process conditions & & $\mathrm{m}^{2} / \mathrm{s}$ & 0.0000974 \\
\hline \multicolumn{4}{|l|}{ Adimensional number } \\
\hline Reynolds & $/ /$ & & $500,000.00$ \\
\hline Schmidt & $/ /$ & & 0.17 \\
\hline Sherwood (laminar flux) & $/ /$ & & 258.23 \\
\hline \multicolumn{4}{|l|}{ Evaporated water flow } \\
\hline Conveying material transport coefficient & $\mathrm{m} / \mathrm{s}$ & & 0.0279 \\
\hline Flow of water evaporated from one half of the tank & $\mathrm{kg} / \mathrm{s}$ & & 0.0232 \\
\hline \multirow{2}{*}{ Total evaporated water flow } & $\mathrm{kg} / \mathrm{s}$ & & 0.0464 \\
\hline & $\mathrm{kg} / \mathrm{d}$ & & 4012.09 \\
\hline
\end{tabular}

Table 8 shows the calculation of the power transmitted to the air through latent heat.

Table 8. Power transferred during evaporation

\begin{tabular}{lll}
\hline Latent heat of vaporization at operating conditions & $\mathrm{kJ} / \mathrm{kg}$ & 2362.37 \\
Thermal power transferred & $\mathbf{k W}$ & $\mathbf{1 0 9 . 7 0}$ \\
\hline
\end{tabular}




\section{AJAST}

Asian Journal of Applied Science and Technology

Volume 4, Issue 4, Pages 105-129, October-December 2020

The thermophysical parameters used in Table 7 have been obtained from tables showing the properties of air (Moran et al., 2011; Magrini \& Magnani, 2009).

The value of the binary diffusivity was obtained from suitable diagrams in conditions of pressure and temperature equal to $1 \mathrm{~atm}$ and $300 \mathrm{~K}$; to bring it back to the process conditions, the following formula was applied, remembering that the binary diffusivity of the perfect gases is approximately proportional to the relation:

$$
D_{A B}=D_{A B(300 K ; 1 a t m)}\left(\frac{P}{P_{e x}}\right)\left(\frac{T_{e x}}{T}\right)^{1,75} \quad\left[\frac{m^{2}}{s}\right]
$$

where $P_{e x}$ and $T_{e x}$ represent the pressure and operating temperature, expressed in atmospheres and Kelvin (Subramanian, p. 1).

The value of the latent heat was evaluated at the working pressure through the aforementioned tables; in order to bring it back to the temperature conditions of the system, the Watson correlation was exploited (Pantani, 2010, p. $10)$ :

$$
r_{p, t_{e x}}=r_{p_{e x}}\left(\frac{T_{c}-T_{e x}}{T_{c}-T_{e b}}\right)^{0,38} \quad\left[\frac{k J}{k g}\right]
$$

where:

- $\quad r_{p_{e x}}[\mathrm{~kJ} / \mathrm{kg}]:$ latent heat of vaporization at working pressure;

- $T_{c}[K]$ : critical temperature, equal to $647 \mathrm{~K}$;

- $T_{e b}[K]$ : boiling temperature at operating pressure conditions, equal to $342.25 \mathrm{~K}\left(69.1^{\circ} \mathrm{C}\right)$.

With the conditions of speed, pressure and temperature adopted, it is possible to push the system up to a daily production of approximately $4000 \mathrm{~kg} / \mathrm{d}$ of evaporated water. This will be the maximum condensable amount in the system. The peculiarity of this process lies in the possibility of fully recovering the latent heat of vaporization, quantified in a power value of approximately $110.00 \mathrm{~kW}$.

\subsection{Primary heat exchanger}

The main heat exchanger performs a triple function:

- It transmits the thermal energy necessary to raise the salty water temperature near the free surface from its initial value up to the process temperature;

- It transmits the thermal energy needed to replenish leaks through the enclosure, helping to keep the temperature at the operating level;

- Through an adequate control of the delivery and return temperatures, it creates a thermal gradient between the central area near the thermal tunnel and the side walls of the casing; this configuration allows the majority of the evaporated water to be concentrated in the area closest to the expanded sheets, promoting the rotation of convective motions in the right direction. 
Asian Journal of Applied Science and Technology

Volume 4, Issue 4, Pages 105-129, October-December 2020

As stated in paragraph 4.1.3, the use of corrugated pipes has been chosen, firstly because they promote the turbulent motion, thus increasing the convective heat exchange coefficient and the amount of energy transmissible per unit of length, and secondly because it is thought that the turbulent motion creates micro-vibrations which, when transmitted to the salt water at the free surface, promote its evaporation.

The preliminary evaluation of the heat exchange was performed by putting in conservative conditions and carrying out the calculation assuming the use of a smooth tube. In the tank there will be two exchangers of this type, one placed in each half of the tank, and both return flow connections will be connected to the heat generators through two suitable hydraulic manifolds.

Table 9 shows the summary of the calculations.

Table 9. Primary heat exchanger sizing

\begin{tabular}{|c|c|c|}
\hline \multicolumn{3}{|l|}{ Operating temperature } \\
\hline Delivery temperature & ${ }^{\circ} \mathrm{C}$ & 75.00 \\
\hline Return temperature & ${ }^{\circ} \mathrm{C}$ & 45.00 \\
\hline \multicolumn{3}{|l|}{ Piping } \\
\hline Outer diameter & $\mathrm{mm}$ & 32.00 \\
\hline Thickness & $\mathrm{mm}$ & 1.50 \\
\hline Internal diameter & $\mathrm{mm}$ & 29.00 \\
\hline \multicolumn{3}{|l|}{ Operating data } \\
\hline Internal speed to the pipes & $\mathrm{m} / \mathrm{s}$ & 1.50 \\
\hline Fresh water density & $\mathrm{kg} / \mathrm{m}^{3}$ & 1000.00 \\
\hline Fresh water specific heat & $\mathrm{kJ} / \mathrm{kgK}$ & 4.186 \\
\hline \multicolumn{3}{|l|}{ Flow } \\
\hline Volumetric flow rate exchanger - half tank & $\mathrm{m}^{3} / \mathrm{h}$ & 3.57 \\
\hline Total volumetric flow & $\mathrm{m}^{3} / \mathrm{h}$ & 7.13 \\
\hline \multicolumn{3}{|l|}{ Heat exchanger (half tank) } \\
\hline Step (distance between two contiguous hole centres) & $\mathrm{m} / \mathrm{MU}$ & 0.082 \\
\hline Number of passes approximated down & MU & 10.00 \\
\hline Estimated pipe length & $\mathrm{m}$ & 93.00 \\
\hline \multicolumn{3}{|l|}{ Power transmissible } \\
\hline Thermal power transmissible from the single exchanger & $\mathbf{k W}$ & 124.42 \\
\hline
\end{tabular}

To ensure that the correct transversal temperature gradient is present in the tank, it has been decided to perform the control monitoring of the temperature of the return fluid to the system; once this reaches the preset value, knowing that of the delivery temperature, the sending of thermal energy can be stopped. 


\subsection{Condensate production}

The evaluation of the production of condensate must take into account the fact that it is subordinate to the quantity of evaporating water. As previously explained, in the best operating conditions the maximum amount of condensable water will be equal to the maximum evaporating quantity; it will therefore be necessary to size the thermal tunnel condenser in such a way as to allow condensation of this quantity of water. To calculate the amount of condensate produced, it is necessary to know the thermo-hygrometric conditions of the humid air inside the tank before and after condensation and to know the dry air flow to determine the sizing power of the exchangers. Table 10 shows the results of applying the model.

Table 10. Condensing power

\begin{tabular}{lll}
\hline Hygrometric condition & & \\
\hline Specificy humidity - humidified air & $\mathrm{g}_{\mathrm{v}} / \mathrm{kg}_{\mathrm{as}}$ & 1240.00 \\
Specific humidity - dehumidified air & $\mathrm{g}_{\mathrm{v}} / \mathrm{kg}_{\mathrm{as}}$ & 102.80 \\
\hline Condensate production & & \\
\hline Amount of specific condensate & $\mathrm{g}_{\mathrm{v}} / \mathrm{kg}_{\mathrm{as}}$ & 1137.20 \\
\hline Air flow needed & & \\
\hline & & \\
Mass flow of dry air & $\mathrm{kg} / \mathrm{s}$ & 0.04 \\
& $\mathrm{~kg} / \mathrm{h}$ & 147.00 \\
Partial pressure of dry air & $\mathrm{Pa}$ & $10,056.24$ \\
Dry air specific constant & $\mathrm{J} / \mathrm{kgK}$ & 287.00 \\
& $\mathrm{~kg} / \mathrm{s}$ & 0.39 \\
Mass flow of moist air & $\mathrm{kg} / \mathrm{h}$ & 1397.05 \\
& & \\
Condensing power & $\mathrm{kJ} / \mathrm{kg}$ & 3300.00 \\
\hline Enthalpy moist air - humidified air & $\mathrm{kJ} / \mathrm{kg}$ & 293.00 \\
Enthalpy moist air - dehumidified air & $\mathrm{kJ} / \mathrm{kg}$ & 125.79 \\
Enthalpy of condensed & $\mathbf{k W}$ & $\mathbf{- 1 1 6 . 9 5}$ \\
Condensation power & & \\
\hline
\end{tabular}

To be able to condense the same amount of water that evaporates, it is necessary to create an exchange surface that allows the absorption of a thermal power equal to $116.95 \mathrm{~kW}$. This must be ensured through a suitable sizing of the stretched sheets of the thermal tunnel. As can be seen, the resulting power is slightly higher than that calculated for the evaporation, because it also considers the enthalpy contained in the condensate and not only that of the humid air to the initial and final states of the transformation.

\subsection{Condensation support - expanded sheets}

The thermal power necessary to be able to condense the same flow of water that evaporates must be absorbed by a suitable heat exchanger which, in the case study, has a double function: 
- It enables heat exchange and disposal of large amount of energy transferred during the condensation phase;

- It allows the condensed water to percolate above it up to a collecting channel.

In addition to having the proper thermal properties to be used for the purpose, therefore, it must also have mechanical characteristics such as to make it an excellent support on which the condensed water can adhere. The disposition of the expanded metal sheets must be made in such a way as to minimize the interference between adjacent sheets, maximizing the interaction between the fluid and the exchange surface. Moreover, the opening of the expanded metal sheets in the upper part of the system must be made in such a way that the minimum inclination of the plate, with respect to the horizontal, enables the adhesion forces to allow the condensate drop to adhere to the metal surface and to percolate towards the collection system, avoiding it falling into the tank. The mathematical modelling of these aspects requires complex analyses in the field of microfluidics, since the common calculation models that analyze macroscopic phenomena are not representative. For the preliminary dimensioning, it was preferred to obtain the value of the maximum inclination angle experimentally, observing the behavior of a drop of water in contact with an aluminum surface inclined with ever increasing slopes. The result shows that, to ensure the rapid disposal of condensate drops, preventing them from being detached, the outer sheets must form an angle of no less than approximately $50^{\circ}$. Below this value it has been observed that the drop speed decreases, causing an increase of mass and the consequent detachment from the contact surface.

Table 11 shows the results of the application of the calculation method.

Table 11. Thermal tunnel sizing

\begin{tabular}{lll}
\hline Presumed temperature at the base of the thermal tunnel & ${ }^{\circ} \mathrm{C}$ & 20.00 \\
Convective coefficient at the base of the tunnel & $\mathrm{W} / \mathrm{m}^{2} \mathrm{~K}$ & 3149.20 \\
Reduction hypothesis due to the insulating overlap & $\%$ & $30.00 \%$ \\
Presumptive convective coefficient & $\mathrm{W} / \mathrm{m}^{2} \mathrm{~K}$ & 944.76 \\
Thermal conductivity of aluminum & $\mathrm{W} / \mathrm{mK}$ & 210.00 \\
Expanded metal commercial surface & $\mathrm{m}^{2}$ & 2.00 \\
Equivalent metal surface & $\mathrm{m}^{2}$ & 1.54 \\
Fin length & $\mathrm{m}$ & 0.80 \\
"m" coefficient of the fin & $1 / \mathrm{m}$ & 67.07 \\
"A" coefficient of the fin & $\mathrm{K}$ & -40.00 \\
"B" coefficient of the fin & $\mathrm{K}$ & 0.00 \\
Specific thermal flow & $\mathrm{kW} / \mathrm{fin}$ & -0.90 \\
Number of fins & fin & $\mathbf{1 5 . 0 0}$ \\
\hline
\end{tabular}

The base of the thermal tunnel is a region with high thermal conductivity and is in direct contact with the colder water at the bottom of the tank. Therefore, its temperature has been hypothesized not to be much higher than that at the bottom. In order to avoid the heat developed by the main heat exchanger being transmitted to the expanded 


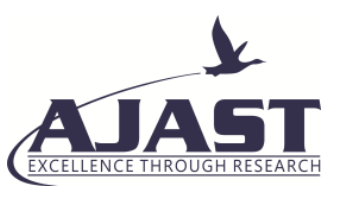

Asian Journal of Applied Science and Technology

Volume 4, Issue 4, Pages 105-129, October-December 2020

sheets, disturbing the absorption of thermal energy during condensation, the insulation panels of the thermal tunnel will be extended beyond the base for a certain length, which will be established during the project execution. This extension is thought to lead to a significant reduction in the convective heat exchange coefficient between the base of the thermal tunnel and the air to be dehumidified. Therefore, to consider this phenomenon, a reduction of $30 \%$ was considered. The expanded metal will exit the base of the thermal tunnel for a length equal to $80 \mathrm{~cm}$, and the remaining part will pass through the thermal tunnel and will be immersed in the coldest salty water at the bottom of the tank. The number of rows has been evaluated assuming the support of nine stretched sheets to form an extension having a length equal to $9 \mathrm{~m}$. For compatibility with the capacity of the industrial processes available, in the executive design phase it will be evaluated, together with the manufacturing companies, the best method to join the sheets.

\subsection{Heat generation}

As explained in the previous sections, the SDGC system is designed to be able to self-maintain when brought to operating temperatures. For this purpose, it was decided to use two different heat generators:

- Solar thermal system: this operates mainly under the regime conditions in order to reintegrate the heat losses through the casing;

- Heat pump system: this operates mainly at start-up, in order to bring salt water from the feed from the conditions in the tank up to the average operating temperature.

However, while the two plants can work in synergy to reduce the start-up times, solar thermal will be the primary generator once the SDGC system has reached the full capacity.

\subsubsection{Solar thermal generator}

For the case study, the use of vacuum solar collectors was chosen because of their ability to bring the water to high temperatures, in harmony with those of operating the plant. The type of collector chosen for sizing is the Sky Pro 18 model produced by the company Kloben Industries S.r.l, having the characteristics of interest shown in Table 12.

Table 12. Kloben Sky Pro 18

\begin{tabular}{lll}
\hline Optical efficiency & $\%$ & $71.80 \%$ \\
Opening surface & $\mathrm{m}^{2}$ & 3.43 \\
Absorption surface & $\mathrm{m}^{2}$ & 4.65 \\
Heat loss - 1st order & $\mathrm{W} / \mathrm{m}^{2} \mathrm{~K}$ & 1.051 \\
Heat loss - 2nd order & $\mathrm{W} / \mathrm{m}^{2} \mathrm{~K}$ & 0.004 \\
\hline
\end{tabular}

The sizing of the collectors was carried out assuming installation of the plant in Milan and considering the operating system for $8000 \mathrm{~h} /$ year.

To obtain a datum concerning the minimum number of collectors necessary, it was decided to calculate the global radiation assuming installation of the collector in the best possible operating conditions, which are: 
- Geographic orientation in the SOUTH direction (azimuth equal to $0^{\circ}$ );

- Angle of inclination on the horizontal optimal for the operation of solar panels $\left(35^{\circ}\right)$;

- Absence of shadowing and obstacles.

Under these assumptions, the operational efficiency of the collector was calculated using the following formula (Battisti, 2013, p. 17):

$$
\eta=\eta_{o}-\frac{k_{1}}{I} \Delta T-\frac{k_{2}}{I} \Delta T^{2}
$$

in which:

- $\eta_{o}[\%]$ : optical efficiency of the collector. This represents the amount of solar radiation reflected on the collector's opening surface that can be transformed into useful thermal energy, calculated under certain measurement conditions.

- $\quad k_{1}, k_{2}\left[\mathrm{~W} / \mathrm{m}^{2} \mathrm{~K}\right]$ : thermal dispersion coefficients. These quantify the amount of thermal energy lost by conduction through the collector material, thermal radiation and convection.

- $\quad \Delta T\left[K\right.$ or $\left.{ }^{\circ} \mathrm{C}\right]:$ difference between the average temperature inside the collector and the external environment;

- $\quad I\left[W / m^{2}\right]$ : effective irradiation on the collector.

Once the operating efficiency of the collector have been calculated, the radiation actually transmitted to the water from the collectors was evaluated and from this the necessary surface was found for the heat exchange to take place. Finally, the number of collectors needed was calculated; as a characteristic data for the calculation, the opening surface is used more and more, but also the absorption surface is taken into consideration. In the calculations it is therefore essential to discriminate the source of the results according to the two surfaces considered. In the case study, the number of collectors was evaluated using both surfaces and choosing the one with the largest number of collectors. Table 13 shows the results of the calculations performed.

Table 13. Solar collectors sizing

\begin{tabular}{lll}
\hline Energy losses from the tank & & \\
\hline Hours of operation per year & $\mathrm{h} / \mathrm{year}$ & 8000.00 \\
Annual energy loss & $\mathrm{kWh} / \mathrm{year}$ & 8276.80 \\
\hline Solar radiation on inclined surface & & \\
\hline Location & $/ /$ & Milan \\
Azimuth & $\circ$ & 0.00 \\
Inclination with respect to the horizontal plane & $\circ$ & 35.00 \\
Reflection coefficient on the ground & $/ /$ & 0.20 \\
Shadows and obstacles & $/ /$ & none \\
\hline
\end{tabular}




\begin{tabular}{lll}
\hline Global radiation on inclined surface & $\mathrm{kWh} / \mathrm{m}^{2} \mathrm{year}$ & 1612.00 \\
Irradiation on inclined surface & $\mathrm{W} / \mathrm{m}^{2}$ & 184.02 \\
\hline Solar collectors operating efficency & & \\
\hline Thermal medium fluid temperature & ${ }^{\circ} \mathrm{C}$ & 60.00 \\
Average annual room temperature & ${ }^{\circ} \mathrm{C}$ & 13.00 \\
Collector operational efficiency & $\%$ & $40.15 \%$ \\
\hline Solar collectors numbers & & \\
\hline Effective radiation absorbed by the collector & $\mathrm{kWh} / \mathrm{m}^{2} \mathrm{year}$ & 647.29 \\
Exchange surface required & $\mathrm{m}^{2}$ & 12.79 \\
Number of collectors - opening surface & $/ /$ & 4.00 \\
Number of collectors - absorption surface & $/ /$ & 3.00 \\
Numbers of solar collectors & $/ /$ & $\mathbf{4 . 0 0}$ \\
\hline
\end{tabular}

Therefore, the minimum number of collectors required, calculated in the best operating conditions, is four.

\subsubsection{Heat pump generator}

To allow a rapid achievement of the expected operating conditions, it was considered appropriate to assist the solar thermal system through the use of a second heat generator. Among the various choices available on the market, the one that most reflects the need to have an efficient and low environmental impact energy source is the heat pump technology. In a first evaluation it was decided to couple the heat pump to a suitably sized geothermal probe system. However, the costs for the geological analyses and, above all, for the drilling of the ground and the installation of the probes did not justify the use of the system. As explained previously, in fact, it is needed the heat pump to run at full capacity only during start-ups which, for the good functioning of the system, should be reduced to the minimum number needed. Therefore, it is easy to understand that investing excessive resources for a technology that will be used very rarely is uneconomic. For the case study it was therefore decided to use a water / water heat pump, in which the evaporator is in communication with a thermocouple.

Introduction to the thermal flywheel: this system consists of an artificial waterproof well with a volume of a few tens of cubic meters, capable of accumulating the thermal energy of the superficial layers of the ground, also acting as a thermal flywheel to store the excess heat produced, for example, from a solar collector. This system, which will be integrated in the future development of the SDGC system, allows the storage and exploitation of the heat of the ground at reasonable costs compared to the more expensive geothermal probes (Lavanga \& Sparacino, Termopozzo, 2013).

The calculations for the case study were made taking into account the Vitocal 300-G heat pump, model WW 301.A21, produced by the company Viessmann GmbH. This machine is able to operate both as a ground / water heat pump and as a water / water heat pump. Table 14 shows the main operating data. 
Table 14. Vitocal 300-G datasheet

\begin{tabular}{|c|c|c|}
\hline \multicolumn{3}{|l|}{ Performance data - EN 14511} \\
\hline Operating conditions & $/ /$ & W10/W35 \\
\hline Useful power & $\mathrm{kW}$ & 28.10 \\
\hline Refrigeration power & $\mathrm{kW}$ & 23.70 \\
\hline Electric power absorbed & $\mathrm{kW}$ & 4.73 \\
\hline Performance coefficient (COP) & $/ /$ & 5.94 \\
\hline \multicolumn{3}{|l|}{ Primary circuit (evaporator) } \\
\hline Capacity & 1 & 6.50 \\
\hline Minimum volumetric flow rate & $1 / \mathrm{h}$ & 5200.00 \\
\hline Loss of load & $\mathrm{kPa}$ & 17.00 \\
\hline Maximum flow temperature (ground circuit input) & ${ }^{\circ} \mathrm{C}$ & 25.00 \\
\hline Minimum flow temperature (ground circuit input) & ${ }^{\circ} \mathrm{C}$ & 7.50 \\
\hline \multicolumn{3}{|l|}{ Secondary circuit (condenser) } \\
\hline Capacity & 1 & 6.50 \\
\hline Minimum volumetric flow rate & $1 / \mathrm{h}$ & 1900.00 \\
\hline Loss of load & $\mathrm{kPa}$ & 3.80 \\
\hline Maximum flow temperature & ${ }^{\circ} \mathrm{C}$ & 60.00 \\
\hline
\end{tabular}

For a first analysis we chose to operate conditions $W 10 / W 55$. In this way the salt water will be brought to the temperature of $55^{\circ} \mathrm{C}$ and the solar thermal plant will be responsible for compensating the small temperature difference between the heat pump regime and the average operating temperature. It was decided to operate in this way to avoid a too high penalty on the COP. Table 15 shows the results of the calculations performed.

Table 15. Vitocal 300-G - operating conditions

\begin{tabular}{lll}
\hline Energy requirements & & \\
\hline Salt water temperature at the entrance & ${ }^{\circ} \mathrm{C}$ & 15.00 \\
Operating temperature for heat pump & ${ }^{\circ} \mathrm{C}$ & 55.00 \\
Specific salt water heat & $\mathrm{kJ} / \mathrm{kgK}$ & 3.93 \\
Salt water density & $\mathrm{kg} / \mathrm{m}^{3}$ & 1025.00 \\
Mass to be heated & $\mathrm{kg}$ & 5147.55 \\
Thermal energy to be supplied & $\mathbf{k W h}$ & $\mathbf{2 2 4 . 4 9}$ \\
\hline Heat pump - operating conditions & & \\
\hline Thermal power yield & $\mathrm{kW}$ & 24.92 \\
\hline
\end{tabular}




\begin{tabular}{lll}
\hline Performance coefficient (COP) & $/ /$ & 3.68 \\
Electric power absorbed & $\mathrm{kW}$ & 6.77 \\
\hline Hours of operation & & \\
\hline Time needed to go to full capacity & $\mathbf{h}$ & $\mathbf{9 . 0 1}$ \\
\hline
\end{tabular}

In the calculation, the volume (and consequently the mass) of salty water to be heated was considered equal to $30 \%$ of the whole salty water mass inside the tank, again because the objective is to heat only the portion of fluid near the free surface. The results show that, in those operating conditions, for the plant to be able to operate through only the thermal energy provided by the solar plant, it will take around $9 h$, which is a decidedly good start time. Figure 7 shows a simplified Process and Instrumentation Diagram of the SDGC plant with heat generators.

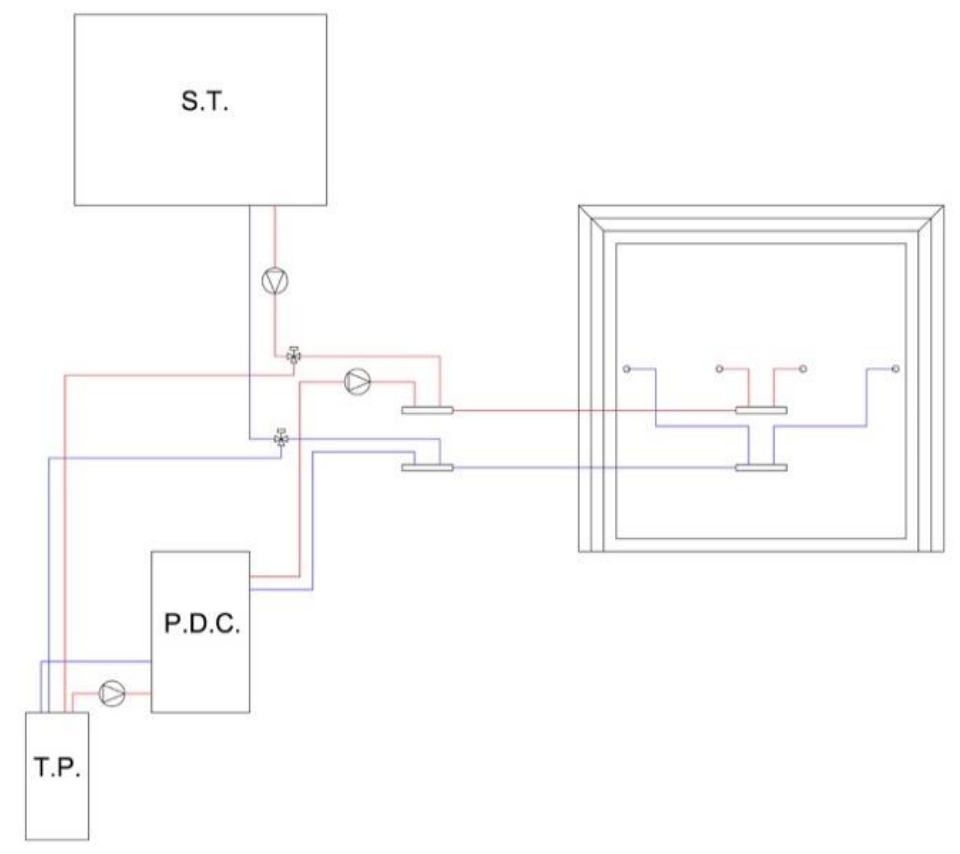

Figure 7. SDGC simplified P\&ID

\section{Conclusions and Future developments}

This paper has presented the development of the Solar Desalination Geoassisted Continuous system, a new and innovative type of system for desalinating marine or brackish waters through a sustainable use of energy.

The analysis model, presented in a previous article of the same author, makes it possible to relate the geometrical and thermophysical parameters to the operating conditions of the plant, allowing an easy-to-use formulation to be obtained for calculating the producibility of the plant.

Based on the calculation model, it was possible to make a preliminary sizing of the main parts and components. In this development phase, particular attention was paid to the standardization of the system, choosing to assemble elements commonly available in the industrial sector, paying more attention to the functionality and effectiveness of the element and leaving the system optimization for future development in relation to the choice of using products and materials made to measure for a specific function. The result has led to the determination of a standard 


\section{AJAST}

Asian Journal of Applied Science and Technology

Volume 4, Issue 4, Pages 105-129, October-December 2020

module, characterized by a good level of producibility in terms of condensed water, which could be appropriately replicated to obtain the level of productivity sought by a possible user. In a following paper, it will be presented the economic analysis, aimed at estimating the necessary initial investment, the operating costs incurred during the operation of the plant, and the relative comparison with similar plants. Furthermore, a global comparison with the other technologies will be presented, in order to highlight the advantages and disadvantages of the SDGC system.

\section{Acknowledgments}

Dr. Vito Lavanga, freelance researcher and inventor.

\section{Patents}

Lavanga Vito, Farné Stefano - METHOD FOR THE CONTINUOUS DESALINIZATION AND DEVICE FOR THE IMPLEMENTATION OF SAID METHOD

Publication Number WO/2016/162896 - Publication Date 13.10.2016

SDGC https://patentscope.wipo.int/search/en/detail.jsf?docId=WO2016162896 (sea and process water solar desalination)

\section{References}

Ayoub, G.M., \& Malaeb, L. (2014) Economic feasibility of a solar still desalination system with enhanced productivity, Desalination, Vol. 335, No. 1, pp.27-32.

Bacha, B.H. (2013) Dynamic modeling and experimental validation of a water desalination prototype by solar energy using humidification-dehumidification process, Desalination, Vol. 332, pp.182-208.

Battisti, R. (2013) Impianti solari termici per reti di teleriscaldamento, Dario Flaccovio, Palermo.

Calza, F. (2010) Manuale degli impianti termici e idrici, Tecniche Nuove, Milano.

Cervinia, V.M., Masaki, O., Tetsuji, O., Satoshi, N., \& Wataru, N. (2016) Effect of biofilm on inorganic suspended solids accumulation on reverse osmosis membranes, Japan Society On Water Environment, Vol. 14, No. 5, pp. 308-318.

Chang, Z., Zheng, H., Yang, Y., Su, Y., \& Duan, Z. (2014) Experimental investigation of a novel multi-effect solar desalination system based on humidification-dehumidification process, Renewable Energy, Vol. 69, pp.253-259.

Cipollina, A., Micale, G., Rizzuti, L (Eds.) (2009) Seawater Desalination: Conventional and renewable energy processes, Springer, New York.

de la Cruz, L., Cynthia, L. (2015) Studio di fattibilità di un impianto di dissalazione ad osmosi inversa con l'utilizzo di energia solare fotovoltaica, Politecnico di Milano, Milano.

Ducci, C. (2012) Studio e dimensionamento di un sistema per la dissalazione e la generazione di energia con accumulo in aree rurali isolate, Padova Digital University Archive, Padova.

El-Agouz, S.A., Abd El-Aziz, G.B., \& Awad, A.M. (2014) Solar desalination system using spray evaporation, Energy, Vol. 76, pp.276-283. 
Farina, A., Santi, A., \& Lavacchielli, G. (2014) Termofluidodinamica applicata, Università degli studi di Parma, Parma.

Farné S. (2020) Theoretical Setting, Mathematical Model and Operating Principles of an Innovative System, Based on Natural Evaporation Processes, for Salty and Brackish Water Purification, Asian Journal of Applied Science and Technology (AJAST), Volume 4, Issue 3, Pages 183-209

Farné S., Lavanga V., Giovenzana V., Beghi R., Guidetti R., Innovative desalination plant based on the use of renewable energy sources, being published

Fratelli Mariani S.p.A. Lamiera stirata in stock, Catalogo tecnico.

Gazebo S.p.A. (2013) Progettazione e costruzione impianti di trattamento acque reflue, Catalogo tecnico prodotti.

Hamed, M., Kabel, A., Omara, Z., \& Sharshir, S. (2014) Mathematical and experimental investigation of a solar humidification-dehumidification desalination unit, Desalination, Vol. 358, pp.9-17.

Kabeel, A.E., \& El-Said, E.M. (2013) Applicability of flashing desalination technique for small scale needs using a novel integrated system coupled with nanofluid-base solar collector, Desalination, Vol. 333, No. 1, pp.10-22.

Kang, H., Yang, Y., Chang, Z., Zheng, H., \& Duan, Z. (2014) Performance of a two-stage multi-effect desalination system based on humidification-dehumidification process, Desalination, Vol. 344, pp.339-349.

Lavanga, V., \& Farné, S. (2017) Patent n. 0001427399.

Lavanga, V., \& Farné, S. (2016) Patent n. 102015902343234.

Lavanga, V., \& Sparacino, A.C. (2013) Patent n. 0000275666.

Li, X., Yuan, G., Wang, Z., Li, H., \& Xu, Z. (2014) Experimental study on a humidification and dehumidification desalination system of solar air heater with evacuated tubes, Desalination, Vol. 351, pp.1-8.

Magrini, A., \& Magnani, L. (2009) Fisica Tecnica: Volume 1 - Esempi di calcolo di termodinamica e trasmissione del calore, CittàStudi Edizioni, Torino.

Manokar, A.M., Murugavel, K.K., \& Esakkimuthu, G. (2014) Different parameters affecting the rate of evaporation and condensation on passive solar still - A review, Renewable and Sustainable Energy Reviews, Vol. 38, pp.309-322.

Massarutto, A. (2008) L'acqua, Il Mulino, Bologna.

Moran, M., Shapiro, H., Munson, B., \& DeWitt, D. (2011) Introduction to thermal systems engineering, McGraw Hill, New York.

Nagapadma M., Rakesh M., Nanditha N., Sushma K. M. \& Bhargavi K. S. (2019) Desalination of Seawater Using Graphene oxide Membrane, Asian Journal of Applied Science and Technology (AJAST), Volume 3, Issue 3, Pages 202-206, July-September 2019 
Nam, W.K., Seockheon, L., Dooil, K., Seungkwan, H., \& Ji, H.K. (2011) Analyses of calcium carbonate scale deposition on four RO membranes under a seawater desalination condition, Water Science \& Technology Journal, Vol. 64, No. 8, pp.1573-1580.

Nematollahi, F., Rahimi, A., \& Gheinani, T.T. (2013) Experimental and theoretical energy and exergy analysis for a solar desalination system, Desalination, Vol. 317, pp.23-31.

Pantani, R. (2010) Effetti termici nelle trasformazioni. Principi di ingegneria chimica ambientale, Università di Salerno, Salerno.

Park, G.L., Schafer, A.I., \& Richards, B.S. (2012) The effect of intermittent operation on a wind-powered membrane system for brackish water desalination, Water Science \& Technology Journal, Vol. 65, No. 5, pp.867-874.

Ramadan, M.R., El-Sebali, A.A., Aboul-Enein, S., \& Khallaf, A.M. (2004) Experimental testing of a shallow solar pond with continuous extraction, Energy and Buildings, Vol. 36, No. 9, pp.955-964.

Reddy, S., \& Sharon, H. (2014) A review of solar energy driven desalination technologies, Elsevier, New York.

Rognoni, M. (2010) La dissalazione dell'acqua di mare. Descrizione, analisi e valutazione delle principali tecnologie, Dario Flaccovio, Palerno.

Salata, F., \& Coppi, M. (2014) A first approach study on the desalination of sea water using heat transformer powered by solar ponds, Applied Energy, Vol. 136, pp.611-618.

Schafer, A.I., Remy, C., \& Richards, B.S. (2004) Performance of a small solar-powered hybrid membrane system for remote communities under varying feedwater salinities, Water Science \& Technology: Water Supply, Vol. 5, No. 5-6, pp.233-243.

Stiferite S.r.l. (2017) Prodotti \& soluzioni per edifici efficienti, Catalogo Tecnico.

Subramanian, S. (s.d.) Lecture notes on the estimation of binary diffusivities, Clarkson University, Clarkson.

Tang, M., Cox, R., \& Kalberer, M. (2014) Compilation and evaluation of gas phase diffusion coefficients of reactive trace gases in the atmosphere: volume 1. Inorganic compounds, Atmospheric Chemistry and Physics, Vol. 14, No. 17, pp.9233-9247.

Tzen, E., Zaragoza, G., \& Alarcòn Padilla, D.C. (2012) Solar Desalination, Comprehensive Renewable Energy, Vol. 3, pp.529-565.

UN Water (2016). 2016 UN World Water Development Report, Water and Jobs.

World Health Organization. (2017) Guidelines for drinking-water quality, United Nations, Geneva.

Yildirim, C., \& Solmus, I. (2014). A parametric study on a humidification-dehumidification desalination unit powered by a solar air and water heaters, Energy Conversion and Management, Vol. 86, pp.568-575. 